\title{
Assessment of 25-Hydroxyvitamin D Levels in Patients with Resistant Hypertension
}

\author{
Erdal Belen $^{a}$ İrfan Şahin ${ }^{b}$ Barış Güngörc Burak Ayça ${ }^{a}$ İlhan İlker Avcı ${ }^{b}$ \\ Murat Avşar ${ }^{a}$ Suleyman Sezai Yıldız ${ }^{b}$ Fatih Akın ${ }^{d}$ Emrah Bozbeyoglu ${ }^{c}$ \\ Ertugrul Okuyan ${ }^{\text {b }}$
}

Department of Cardiology at a Okmeydanı Training and Research Hospital, ${ }^{\mathrm{b}}$ Bagcilar Education and Research Hospital, and 'Siyami Ersek Thoracic and Cardiovascular Surgery Training and Research Hospital, Istanbul, and ${ }^{\mathrm{d}}$ Department of Cardiology, Muğla Sitki Kocman University School of Medicine, Muğla, Turkey

\section{Key Words}

Ambulatory blood pressure - Office blood pressure .

Parathormone $\cdot$ Resistant hypertension $\cdot$ Vitamin D

\begin{abstract}
Objective: To investigate the possible correlation between serum 25-hydroxyvitamin D levels and resistant hypertension (RH). Subjects and Methods: Patients who had undergone ambulatory blood pressure measurements (ABPM) during outpatient controls were enrolled. Fifty subjects with $\mathrm{RH}, 50$ with controlled hypertension (CHT) and 50 normotensive subjects (NT) were included in the study. $\mathrm{RH}$ was defined as 'suboptimal blood pressure control despite using 3 antihypertensive agents including a diuretic or need for 4 or more drugs to control blood pressure'. The 25-hydroxyvitamin $D$ and parathormone levels were compared between the groups. Pearson's correlation coefficient test was applied to assess the correlation between 25 -hydroxyvitamin $D$ levels and office blood pressure (BP) and ABPM. Logistic regression analysis was used to determine the independent correlates of RH. Results: The 25-hydroxyvitamin D level was significantly lower in the RH group $(17.02 \pm 5.4 \mathrm{ng} / \mathrm{ml}) \mathrm{com}$ -
\end{abstract}

\begin{tabular}{ll}
\hline KARGER & $\begin{array}{l}\text { ( } 2015 \text { S. Karger AG, Basel } \\
1011-7571 / 15 / 0251-0025 \$ 39.50 / 0\end{array}$ \\
$\begin{array}{l}\text { E-Mail karger@karger.com } \\
\text { www.karger.com/mpp }\end{array}$ & $\begin{array}{l}\text { This is an Open Access article licensed under the terms of the } \\
\text { Creative Commons Attribution-NonCommercial 3.0 Un- } \\
\text { ported license (CC BY-NC) (www.karger.com/OA-license), } \\
\text { applicable to the online version of the article only. Distribu- } \\
\text { tion permitted for non-commercial purposes only. }\end{array}$
\end{tabular}

pared to the CHT $(24.9 \pm 4.8 \mathrm{ng} / \mathrm{ml})$ and NT groups $(28.0 \pm$ $5.7 \mathrm{ng} / \mathrm{ml}, \mathrm{p}<0.001)$. In univariate correlation analysis, 25-hydroxyvitamin $D$ levels had a significant negative correlation with office systolic BP $(r=-0.329, p<0.001)$, office diastolic $B P(r=-0.395, p<0.001)$, systolic ambulatory BP $(r=-0.844$, $p=0.004)$, and diastolic ambulatory $B P(r=-0.567, p=0.005)$. ROC analysis revealed that 25-hydroxyvitamin $D$ levels $<21.50 \mathrm{ng} / \mathrm{ml}$ predicted the presence of RH with a sensitivity of $78 \%$ and a specificity of $79 \%$ (AUC $=0.89,95 \% \mathrm{Cl} 0.83-$ $0.94)$. In the multivariate logistic regression analysis, 25 -hydroxyvitamin $D$ level was independently correlated with the presence of $\mathrm{RH}(\beta 0.660,95 \% \mathrm{Cl} 0.572-0.760, \mathrm{p}<0.001)$. Conclusion: There was an independent correlation between lower 25-hydroxyvitamin D levels and presence of $\mathrm{RH}$.

(c) 2015 S. Karger AG, Basel

\section{Introduction}

Hypertension (HT) is one of the major risk factors for cardiovascular diseases and is closely related to adverse events such as stroke, myocardial infarction and cardiac failure [1]. Despite modern antihypertensive therapies, 
in $10-35 \%$ of HT patients, blood pressure (BP) remains high or is barely controlled with combination therapy [2]. These patients are classified as having resistant hypertension (RH) and have a higher risk of complications. Hyperactivation of the renin-angiotensin system (RAS) has been suggested as the major mechanism of $\mathrm{RH}[3]$.

Recent studies [4-7] have revealed the correlation of 25-hydroxyvitamin $\mathrm{D}$ deficiency with various diseases such as coronary artery disease, heart failure, contrastinduced nephropathy and diabetes mellitus. Vitamin D receptors are broadly expressed by cardiovascular tissues such as endothelial cells, cardiomyocytes and vascular smooth muscle cells and play a role in renin gene expression $[8,9]$. Although a few studies $[10,11]$ investigated 25-hydroxyvitamin D levels in the HT population, the correlation of 25-hydroxyvitamin $\mathrm{D}$ levels in patients with RH has not been studied before. Hence the objective of this study was to investigate the possible correlation between 25-hydroxyvitamin D levels and RH.

\section{Subjects and Methods}

\section{Study Population}

This is a cross-sectional prospective trial conducted at the Hypertension Outpatient Clinic of Okmeydanı Training and Research Hospital, Istanbul, Turkey, from September 2013 to April 2014. In total, 150 subjects were included in the study. The participants were allocated to three groups: an $\mathrm{RH}$ group $(\mathrm{n}=50)$, a controlled hypertension ( $\mathrm{CHT}, \mathrm{n}=50)$ group and a normotensive (NT, $\mathrm{n}=50)$ group.

The following data were collected: socio-demographic details, medical history, risk factors, family history, antihypertensive drugs and accompanying therapies (non-steroidal anti-inflammatory drugs, steroids and oral contraceptive pills). Non-compliance with therapy was assessed for each patient by pill count, patient self-report and also their relatives. Height (in metres) and body weight (in kilograms) were measured to calculate body mass index (BMI, $\mathrm{kg} / \mathrm{m}^{2}$ ). A semiquantitative questionnaire adapted from the Cross-Cultural Activity Participation Study was used to classify the physical activity status of the subjects [12].

Exclusion criteria were secondary HT, any disease of bone metabolism, primary hyperparathyroidism, abnormal liver function (an elevation of transaminase level of more than 3 times the upper limit of normal), chronic kidney disease (estimated glomerular filtration rate, eGFR $<60 \mathrm{ml} / \mathrm{min} / 1.73 \mathrm{~m}^{2}$ ), gastrectomy, intestinal malabsorption and cancer or vitamin $\mathrm{D}$ supplementation. The Institutional Ethics Committee approved the study according to the Declaration of Helsinki and written informed consent was obtained from all the participants.

\section{Measurement of Office and Ambulatory BP}

$\mathrm{BP}$ was measured in a quiet environment with a mercury sphygmomanometer with the patient in a sitting position after
5 min of rest. Systolic and diastolic BP were defined with Korotkoff phase I and V sounds, respectively. The mean of three different readings measured at 5-min intervals was recorded. For each patient, 24-hour ambulatory blood pressure measurements (ABPM) were performed with a Contec PM50 device. ABPM were performed at 15-min intervals between $7 \mathrm{a} . \mathrm{m}$. and $11 \mathrm{p} . \mathrm{m}$. and at 30min intervals between 11 p.m. and 7 a.m.

Subjects who had suboptimal BP control (>140/90 mm Hg for office BP or $>135 / 85 \mathrm{~mm} \mathrm{Hg}$ for mean ambulatory daytime BP) despite using 3 antihypertensive agents including a diuretic or need for 4 or more drugs to control BP were allocated to the $\mathrm{RH}$ group [2]. Patients who had office or mean ambulatory daytime BP below these values with 3 or less antihypertensive drugs were allocated to the CHT group. Patients who did not use any kind of anti-hypertensive drug and whose office BP and ambulatory BP were normal constituted the NT group. White-coat HT was defined as the occurrence of BP values higher than normal when measured in the medical environment, but within the normal range during daily life. Masked $\mathrm{HT}$ was defined as a clinical condition in which a patient's office BP level is $<140 / 90 \mathrm{~mm} \mathrm{Hg}$ but ambulatory or home $\mathrm{BP}$ readings are in the hypertensive range. To exclude white-coat and masked HT, ABPM and office measurements were evaluated together.

\section{Laboratory Evaluation}

For routine biochemical measurements, venous blood samples were obtained after 12-hour fasting. Serum vitamin D levels were measured using the high-performance liquid chromatography method and a Zivak ONH 100 A device. Values $<20 \mathrm{ng} / \mathrm{ml}(<50$ $\mathrm{nmol} / \mathrm{l}$ ) were considered very low, values between 21 and $29 \mathrm{ng} / \mathrm{ml}$ (51-74 nmol/l) were considered low, and values $>30 \mathrm{ng} / \mathrm{ml}(>75$ $\mathrm{nmol} / \mathrm{l}$ ) were considered normal [13]. Serum parathormone (PTH) levels were measured using radioimmunoassay technique and a level of $10-65 \mathrm{pg} / \mathrm{ml}$ was considered normal. The study was conducted during the winter season to minimize the effect of seasonal variation in 25-hydroxyvitamin D levels.

\section{Statistical Analysis}

The continuous variables were expressed as means \pm standard deviation for parameters with normal distribution and medians (interquartile range) for parameters without normal distribution, and categorical variables were expressed as numbers and percentages. Analysis of normality was performed using the Kolmogorov-Smirnov test. ANOVA tests were used for the comparison of continuous variables between the three groups followed by Tukey's test. The $\chi^{2}$ test was used to compare categorical variables between the groups. Pearson's correlation was used to analyse the relationship between continuous variables. Multivariate logistic regression analysis was performed to determine the independent correlates of RH. A power analysis (GPower program) [14] was conducted with an effect size set to 0.25 (medium effect size), and the a level set to $\mathrm{p}<0.05$. A total number of 146 subjects should be recruited to the study to reach an acceptable statistical power of 0.80 . The receiver operating characteristic (ROC) curve was used to show the sensitivity and specificity of 25-hydroxyvitamin D and the optimal cut-off value for predicting RH. The SPSS 17.0 for Windows (SPSS Inc., Chicago, Ill., USA) software package was used in all analyses, and a two-sided $p$ value $<0.05$ was considered significant. 
Table 1. General characteristics of RH, CHT and NT groups

\begin{tabular}{|c|c|c|c|c|}
\hline & $\mathrm{RH}(\mathrm{n}=50)$ & $\mathrm{CHT}(\mathrm{n}=50)$ & $\mathrm{NT}(\mathrm{n}=50)$ & $\mathrm{p}$ \\
\hline Age, years & $60.8 \pm 8$ & $62.06 \pm 8$ & $61.2 \pm 7$ & 0.744 \\
\hline Female/male, n (\%) & $28(56) / 22(44)$ & $30(60) / 20(40)$ & $27(54) / 23(46)$ & 0.827 \\
\hline BMI & $27.01 \pm 2.9$ & $27.4 \pm 2.6$ & $26.8 \pm 2.8$ & 0.524 \\
\hline Systolic BP (office), mm Hg & $137.7 \pm 10.8$ & $126.5 \pm 6.8$ & $125.8 \pm 6.2$ & $<0.001$ \\
\hline Diastolic BP (office), mm Hg & $88.5 \pm 14.1$ & $72.5 \pm 9.5$ & $71.6 \pm 8.2$ & $<0.001$ \\
\hline Systolic BP (ABPM), mm Hg & $132.3 \pm 11.4$ & $124.3 \pm 5.2$ & $118.2 \pm 5.4$ & 0.021 \\
\hline Diastolic BP (ABPM), mm Hg & $83.6 \pm 12.1$ & $74.3 \pm 8.1$ & $70.8 \pm 6.3$ & 0.013 \\
\hline Physical activity (MET-min/week) & $7.1 \pm 2.5$ & $7.7 \pm 2.6$ & $7.4 \pm 2.4$ & 0.528 \\
\hline \multicolumn{5}{|l|}{ Medications, n (\%) } \\
\hline ACEI & $39(78)$ & $34(68)$ & & 0.184 \\
\hline $\mathrm{ARB}$ & $28(56)$ & $16(32)$ & & 0.013 \\
\hline Beta-blocker & $30(60)$ & $18(36)$ & & 0.014 \\
\hline $\mathrm{CCB}$ & $29(58)$ & $20(40)$ & & 0.191 \\
\hline Alpha-blocker & $13(26)$ & $6(12)$ & & 0.062 \\
\hline Diuretic & $50(100)$ & $17(34)$ & & $<0.001$ \\
\hline Statin & $7(14)$ & $9(18)$ & & 0.393 \\
\hline NSAID & $16(32)$ & $15(30)$ & & 0.5 \\
\hline
\end{tabular}

Values are presented as means \pm SD unless specified otherwise. ACEI = Angiotensin-converting enzyme inhibitor; $\mathrm{ARB}=$ angiotensin receptor blocker; $\mathrm{CCB}=$ calcium channel blocker; $\mathrm{MET}=$ metabolic equivalent of task; NSAID = non-steroidal anti-inflammatory drugs.

\section{Results}

The demographic characteristics, BP measurements and medications used are summarized in table 1 . The frequency of gender differences, age and BMI were not different between the study groups. The office systolic and diastolic BP, the ambulatory systolic and diastolic BP measurements were higher in the RH group (office: 137.7 $\pm 10.8 / 88.5 \pm 14.1 \mathrm{~mm} \mathrm{Hg}$, ABPM: $132.3 \pm 11.4 / 83.6 \pm$ $12.1 \mathrm{~mm} \mathrm{Hg}$ ) than in CHT (office: $126.5 \pm 6.8 / 72.5 \pm 9.5$ mm Hg, ABPM: $124.3 \pm 5.2 / 74.3 \pm 8.1 \mathrm{~mm} \mathrm{Hg}$ ) and NT groups (office: $125.8 \pm 6.2 / 71.6 \pm 8.2 \mathrm{~mm} \mathrm{Hg}$, ABPM: $118.2 \pm 5.4 / 70.8 \pm 6.3 \mathrm{~mm} \mathrm{Hg} ; \mathrm{p}<0.001, \mathrm{p}<0.001, \mathrm{p}=$ 0.021 and $\mathrm{p}=0.013$, respectively). The mean number of anti-hypertensive drugs used was significantly higher in the $\mathrm{RH}$ group $(3.9 \pm 0.4)$ compared to the CHT group $(1.72 \pm 0.7, \mathrm{p}<0.01)$. The use of an angiotensin receptor blocker, beta-blocker and diuretics in the RH group was significantly higher when compared to the CHT group [angiotensin receptor blocker: 28 (56\%) vs. $16(32 \%), \mathrm{p}=$ 0.013; beta-blocker: $30(60 \%)$ vs. $18(36 \%), \mathrm{p}=0.014$; diuretic: 50 (100\%) vs. 17 (34\%), p < 0.001, respectively; table 1]. There was no statistical difference between $\mathrm{RH}$ and $\mathrm{CHT}$ groups regarding the frequency of angiotensinconverting enzyme inhibitor, calcium channel blocker, alpha-blocker, non-steroidal anti-inflammatory drug and statin use. Patients in both RH and CHT groups were highly compliant with the medical therapy without a significant difference (98 vs. $96 \%$, respectively, $\mathrm{p}=0.55$ ).

The biochemical parameters of the study groups are given in table 2 . The 25-hydroxyvitamin $\mathrm{D}$ level was significantly lower in the $\mathrm{RH}$ group compared to $\mathrm{CHT}$ and NT groups $(17.02 \pm 5.4,24.9 \pm 4.8$, and $28.0 \pm 5.7 \mathrm{ng} / \mathrm{ml}$, respectively, $\mathrm{p}<0.001)$. PTH level was not statistically different between RH, CHT and NT groups $(39.2 \pm 9.8,37.7$ \pm 8.1 , and $38.8 \pm 7.8 \mathrm{pg} / \mathrm{ml}$, respectively, $\mathrm{p}=0.652$ ).

Univariate correlation analysis showed that 25-hydroxyvitamin $D$ levels were negatively correlated with office systolic BP $(r=-0.329, \mathrm{p}<0.001)$, office diastolic BP $(\mathrm{r}=-0.395, \mathrm{p}<0.001)$, systolic ambulatory BP $(\mathrm{r}=-0.844$, $\mathrm{p}=0.004)$, and diastolic ambulatory BP $(\mathrm{r}=-0.567, \mathrm{p}=$ 0.005; table 3). However, 25-hydroxyvitamin D levels were not significantly correlated with PTH levels (for RH, $r=-0.268, p=0.06$; for CHT, $r=-0.175, p=0.195$; for $\mathrm{NT}, \mathrm{r}=-0.124, \mathrm{p}=0.319)$. Multivariate regression analysis showed that 25 -hydroxyvitamin $\mathrm{D}$ levels remained as the only independent correlate of RH in the study population ( $\beta$ 0.660, 95\% CI 0.572-0.760, $\mathrm{p}<0.001$; table 4 ).

The ROC curve analysis performed to assess the predictive value of 25 -hydroxyvitamin $\mathrm{D}$ for $\mathrm{RH}$ and using 
Table 2. Biochemical parameters of RH, CHT and NT groups

\begin{tabular}{|c|c|c|c|c|}
\hline & $\mathrm{RH}(\mathrm{n}=50)$ & $\mathrm{CHT}(\mathrm{n}=50)$ & $\mathrm{NT}(\mathrm{n}=50)$ & $\mathrm{p}$ \\
\hline Glucose, mg/dl & $80.3 \pm 10$ & $83.1 \pm 11.4$ & $82.2 \pm 11.3$ & 0.456 \\
\hline Creatinine, $\mathrm{mg} / \mathrm{dl}$ & $0.84 \pm 0.09$ & $0.85 \pm 0.12$ & $0.85 \pm 0.11$ & 0.777 \\
\hline $\mathrm{eGFR}, \mathrm{ml} / \mathrm{min} / 1.73 \mathrm{~m}^{2}$ & $89.3 \pm 6.6$ & $85.6 \pm 5.7$ & $87.5 \pm 7.2$ & 0.951 \\
\hline Phosphate, mg/dl & $3.4 \pm 0.6$ & $3.3 \pm 0.7$ & $3.5 \pm 0.6$ & 0.412 \\
\hline Calcium, mg/dl & $8.6 \pm 0.7$ & $8.4 \pm 0.6$ & $8.7 \pm 0.7$ & 0.096 \\
\hline Triglycerides, mg/dl & $139 \pm 38$ & $151 \pm 41$ & $142 \pm 34$ & 0.432 \\
\hline $\mathrm{HDL}-\mathrm{C}, \mathrm{mg} / \mathrm{dl}$ & $49.7 \pm 10.5$ & $45.3 \pm 11.6$ & $46.5 \pm 9$ & 0.387 \\
\hline LDL-C, mg/dl & $122 \pm 24$ & $127 \pm 28$ & $120 \pm 29$ & 0.491 \\
\hline Cholesterol, mg/dl & $193.8 \pm 31.2$ & $207.8 \pm 43.4$ & $203.7 \pm 50.3$ & 0.673 \\
\hline $\mathrm{PTH}, \mathrm{pg} / \mathrm{ml}$ & $39.2 \pm 9.8$ & $37.7 \pm 8.1$ & $38.8 \pm 7.8$ & 0.652 \\
\hline 25-Hydroxyvitamin $\mathrm{D}, \mathrm{ng} / \mathrm{ml}$ & $17.02 \pm 5.4$ & $24.9 \pm 4.8$ & $28.0 \pm 5.7$ & $<0.001$ \\
\hline$<20 \mathrm{ng} / \mathrm{ml}, \mathrm{n}(\%)$ & $17(34)$ & $5(10)$ & $2(4)$ & \\
\hline $21-29 \mathrm{ng} / \mathrm{ml}, \mathrm{n}(\%)$ & $28(56)$ & $29(58)$ & $26(52)$ & \\
\hline$>30 \mathrm{ng} / \mathrm{ml}, \mathrm{n}(\%)$ & $5(10)$ & $16(32)$ & $22(44)$ & \\
\hline
\end{tabular}

HDL-C = High-density lipoprotein cholesterol; LDL-C = low-density lipoprotein cholesterol.

Table 3. Univariate correlates of 25-hydroxyvitamin D in the study population

\begin{tabular}{lcc}
\hline Variable & $\mathrm{r}$ & $\mathrm{p}$ \\
\hline Age (years) & -0.053 & 0.519 \\
BMI & 0.151 & 0.65 \\
Systolic BP (office) (mm Hg) & -0.329 & $<0.001$ \\
Diastolic BP (office) (mm Hg) & -0.395 & $<0.001$ \\
Systolic BP (ABPM) (mm Hg) & -0.844 & 0.004 \\
Diastolic BP (ABPM) (mm Hg) & -0.567 & 0.005 \\
eGFR (ml/min/1.73 m²) & 0.2 & 0.425 \\
Glucose (mg/dl) & -0.084 & 0.305 \\
Creatinine (mg/dl) & 0.130 & 0.112 \\
Calcium (mg/dl) & 0.160 & 0.160 \\
Phosphate (mg/dl) & -0.124 & 0.131 \\
PTH (pg/ml) & -0.143 & 0.81 \\
\hline
\end{tabular}

$21.50 \mathrm{ng} / \mathrm{ml}$ optimal cut-off value of 25 -hydroxyvitamin D for RH gave a sensitivity of $78 \%$ and a specificity of $79 \%$ (AUC = 0.89, 95\% CI 0.83-0.94; fig. 1).

\section{Discussion}

In this study, 25-hydroxyvitamin D levels were significantly lower in patients with RH than in CHT and NT patients. In addition, patients with CHT had lower 25-hydroxyvitamin D levels than NT subjects. This relationship
Table 4. Independent predictors of RH in multivariate logistic regression analysis

\begin{tabular}{llll}
\hline Variable & $\beta$ & $95 \%$ CI & $\mathrm{p}$ \\
\hline Age (years) & 0.963 & $0.903-1.028$ & 0.258 \\
Sex & 1.413 & $0.437-4.570$ & 0.564 \\
BMI & 1.178 & $0.970-1.431$ & 0.9 \\
eGFR (ml/min/1.73 m²) & 0.920 & $0.834-1.151$ & 0.705 \\
PTH (pg/ml) & 0.985 & $0.923-1.051$ & 0.646 \\
25-Hydroxyvitamin D (ng/ml) & 0.660 & $0.572-0.760$ & $<0.001$ \\
LDL-C (mg/dl) & 1 & $0.978-1.023$ & 0.985 \\
Physical activity (MET-min/week) & 0.871 & $0.688-1.102$ & 0.249 \\
Calcium (mg/dl) & 1.367 & $0.806-2.318$ & 0.246 \\
Phosphate (mg/dl) & 0.855 & $0.372-1.965$ & 0.712 \\
\hline
\end{tabular}

LDL-C = Low-density lipoprotein cholesterol; MET = metabolic equivalent of task. was observed regardless of age, BMI, PTH and calcium levels.

In this study, there was no significant correlation between PTH levels and RH but previous studies revealed that there was a relationship between either high serum PTH levels and/or elevated BP [15] and HT development $[16,17]$. Therefore, our study is not in line with the studies which show secondary hyperparathyroidism as one of the reasons why vitamin $\mathrm{D}$ deficiency causes $\mathrm{BP}$ to increase. Our finding that lower 25-hydroxyvitamin D levels are associated with RH independent of PTH levels confirmed
Belen/Şahin/Güngör/Ayça/Avcı/Avşar/ Yıldız/Akın/Bozbeyoglu/Okuyan 


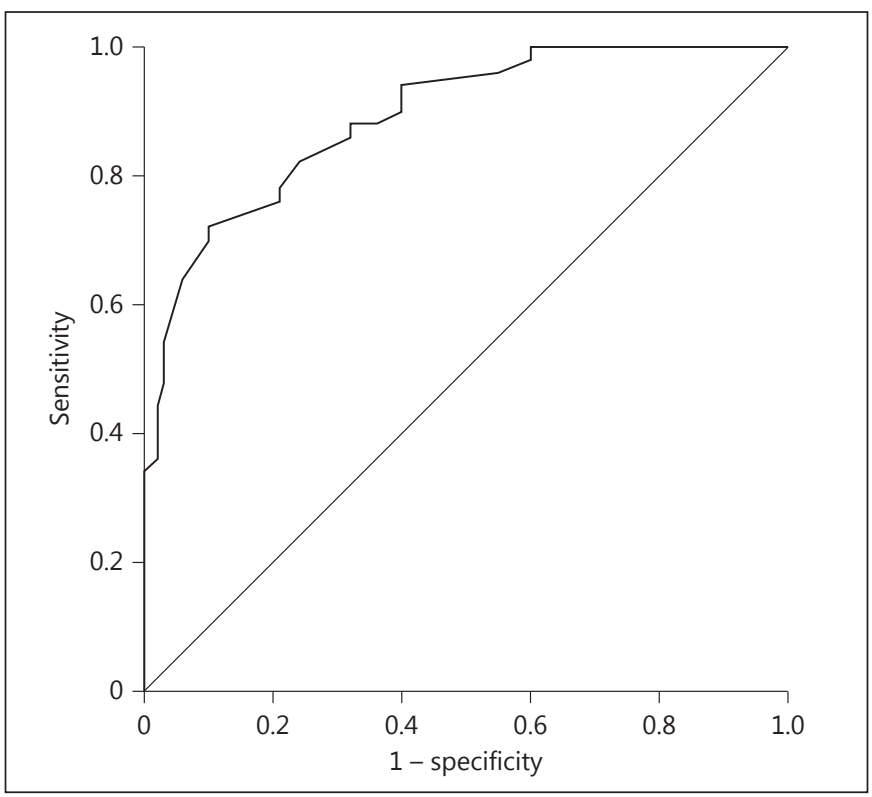

Fig. 1. ROC analysis of 25-hydroxyvitamin D levels for RH prediction.

those of previous studies $[18,19]$. He and Scragg [18] reported an inverse correlation of 25-hydroxyvitamin D levels and a positive correlation of PTH levels with systolic and diastolic BP. However, in multivariate regression analysis only PTH levels were found to be independently correlated with BP. He and Scragg [18] concluded that PTH may mediate most of the association between 25-hydroxyvitamin D levels and increase in BP. However, Zhao et al. [19] determined that 25-hydroxyvitamin D levels are associated with $\mathrm{BP}$ and incidence of $\mathrm{HT}$ and pre-HT independent of PTH measurements. In addition, an independent association of vitamin $\mathrm{D}$ levels with carotid intima media thickness has been shown, which was not present with PTH levels [20]. There are also some factors that influence PTH levels such as daily intake of calcium, phosphate and sodium. However, it is hard to investigate the effect of these parameters on PTH levels and BP [21, 22].

$\mathrm{RH}$ worsens the prognosis of hypertensive patients, leading to higher rates of end organ damage such as left ventricular hypertrophy, microalbuminuria, kidney failure, endothelial dysfunction, carotid artery stiffness, and atherosclerosis [23]. Pathophysiology and precipitating factors of RH have not been clearly established [24], but it is believed that the pathophysiology is multifactorial and RAS plays a major role. Overactivation of the RAS and aldosterone production is generally recognized in se-

Vitamin D and Resistant Hypertension vere $\mathrm{HT}$ and in the accelerated phase of HT [25]. Salt- and volume-independent RAS up-regulation (detected as increased levels of renin and angiotensin II levels) and cardiac hypertrophy were determined in vitamin $\mathrm{D}$ receptor-null mice [26]. However, in the same study, a stimulation of renin expression in cells either treated with $\mathrm{PTH}$ or transfected with the PTH receptor was not observed. Similarly, the independent effect of vitamin D on RAS in humans has been shown by Forman et al. [27]: lower 25-hydroxyvitamin D levels were associated with increased levels of angiotensin II and inadequate response of renal blood flow to angiotensin II in a population of NT subjects with strictly controlled dietary conditions. In several cross-sectional studies, a negative correlation between 25-hydroxyvitamin D and BP has been shown [11]. In some prospective trials, lower 25 -hydroxyvitamin $\mathrm{D}$ levels were found to be an independent predictor of HT after adjustment for the confounding factors such as demographic properties and PTH levels [10, 28]. This association could partially explain the pathophysiology of the association of lower 25-hydroxyvitamin D levels and RH.

Despite broad epidemiological data that describe the relationship between vitamin $\mathrm{D}$ deficiency and arterial HT [29], it is still not clear whether or not vitamin D status has an influence on the therapeutic reduction of BP. Beneficial effects of vitamin D supplementation on vascular health especially in diabetic patients have been reported.

In a double-blind placebo-controlled trial, a single large dose of vitamin $\mathrm{D}\left(100,000 \mathrm{IU}\right.$ vitamin $\left.\mathrm{D}_{2}\right)$ significantly decreased systolic BP by $14 \mathrm{~mm} \mathrm{Hg}$ compared with placebo [30]. Witham et al. [31] have shown that a higher dose of vitamin $\mathrm{D}_{3}(200,000 \mathrm{IU})$ is associated with better lowering of systolic $\mathrm{BP}$ when compared with a lower dose of vitamin $\mathrm{D}_{3}(100,000 \mathrm{IU})$ and placebo in patients with type 2 diabetes mellitus. However, it is not clear whether vitamin $\mathrm{D}$ supplementation is beneficial in the general population for the treatment of HT.

The limitations of our study include its cross-sectional design with a relatively small sample size and the fact that data regarding the therapeutic use of vitamin D supplementation in HT patients could not be obtained. Also, the daily intake of calcium and phosphate, which may influence vitamin D and PTH levels, was not investigated.

\section{Conclusion}

In this study, there was an independent correlation between lower levels of 25-hydroxyvitamin D and the presence of RH. Although it is hard to explain the pathophys- 
iological mechanism of RH and 25-hydroxyvitamin D deficiency, our findings support previous studies about the possible clinical use of vitamin D deficiency and development of HT. Further studies are warranted to investigate the therapeutic use of vitamin D supplementation in patients with $\mathrm{RH}$.

\section{Disclosure Statement}

None.

\section{References}

1 Rosendorff C, Black HR, Cannon CP, et al: American Heart Association Council for High Blood Pressure Research; American Heart Association Council on Clinical Cardiology; American Heart Association Council on Epidemiology and Prevention: Treatment of hypertension in the prevention and management of ischemic heart disease: a scientific statement from the American Heart Association Council for High Blood Pressure Research and the Councils on Clinical Cardiology and Epidemiology and Prevention. Circulation 2007;115:2761-2788.

2 Calhoun DA, Jones D, Textor S, et al: Resistant hypertension: diagnosis, evaluation, and treatment: a scientific statement from the American Heart Association Professional Education Committee of the Council for High Blood Pressure Research. Circulation 2008 117:510-526.

3 Wang ZV, Scherer PE: Adiponectin, cardiovascular function, and hypertension. Hypertension 2008;51:8-14.

4 Sahin I, Okuyan E, Gungor B, et al: Lower vitamin $\mathrm{D}$ level is associated with poor coronary collateral circulation. Scand Cardiovasc J 2014;48:278-283.

5 Belen E, Tipi FF, Aykan AC, et al: Clinical staging in chronic heart failure associated with low vitamin D and elevated parathormone levels. Acta Cardiol 2014;69:665-671.

6 Sahin I, Gungor B, Can MM, et al: Lower blood vitamin D levels are associated with an increased incidence of contrast-induced nephropathy in patients undergoing coronary angiography. Can J Cardiol 2014;30:428-433.

7 Vujosevic S, Borozan S, Radojevic N, et al: Relationship between 25 -hydroxyvitamin $\mathrm{D}$ and newly diagnosed type 2 diabetes mellitus in postmenopausal women with osteoporosis. Med Princ Pract 2014;23:229-233.

8 Temmerman JC: Vitamin D and cardiovascular disease. J Am Coll Nutr 2011;30:167-170.
\2 Li YC, Qiao G, Uskokovic M, et al: Vitamin D: a negative endocrine regulator of the renin angiotensin system and blood pressure. J Steroid Biochem Mol Biol 2004;89-90:387-392.

10 Forman JP, Giovannucci E, Holmes MD, et al: Plasma 25-hydroxyvitamin D levels and risk of incident hypertension. Hypertension 2007; 49:1063-1069.

11 Hintzpeter B, Mensink GB, Thierfelder W, et al: Vitamin D status and health correlates among German adults. Eur J Clin Nutr 2008; 62:1079-1089.

12 Irwin ML, Mayer-Davis EJ, Addy CL, et al: Moderate-intensity physical activity and fasting insulin levels in women: the Cross-Cultural Activity Participation Study. Diabetes Care 2000;23:449-454

13 Holick MF: Vitamin D deficiency. N Engl J Med 2007;357:266-281.

14 Erdfelder E, Faul F, Buchner A: GPower: a general power analysis program. Behav Res Methods Instrum Comput 1996;28:1-11.

15 Jorde R, Svartberg J, Sundsfjord J: Serum parathyroid hormone as a predictor of increase in systolic blood pressure in men. J Hypertens 2005;23:1639-1644.

16 Taylor EN, Curhan GC, Forman JP: Parathyroid hormone and the risk of incident hypertension. J Hypertens 2008;26:1390-1394.

17 Anderson JL, Vanwoerkom RC, Horne BD, et al: Parathyroid hormone, vitamin $\mathrm{D}$, renal dysfunction, and cardiovascular disease: dependent or independent risk factors? Am Heart J 2011;162:331-339.

18 He JL, Scragg RK: Vitamin D, parathyroid hormone, and blood pressure in the National Health and Nutrition Examination Surveys. Am J Hypertens 2011;24:911-917.

19 Zhao G, Ford ES, Li C, et al: Independent associations of serum concentrations of 25-hydroxyvitamin D and parathyroid hormone with blood pressure among US adults. J Hypertens 2010;28:1821-1828.

20 Reis JP, von Mühlen D, Michos ED, et al: Serum vitamin $\mathrm{D}$, parathyroid hormone levels, and carotid atherosclerosis. Atherosclerosis 2009;207:585-590.
21 Bucher HC, Cook RJ, Guyatt GH, et al: Effects of dietary calcium supplementation on blood pressure. A meta-analysis of randomized controlled trials. JAMA 1996;275:1016-1022.

22 Calvo MS, Park YK: Changing phosphorus content of the US diet: potential for adverse effects on bone. J Nutr 1996;126:1168-1180.

23 Sans Atxer L, Oliveras A: Renal sympathetic denervation in refractory hypertension (in Spanish). Med Clin (Barc) 2013;140:263-265.

24 Sarafidis PA: Epidemiology of resistant hypertension. J Clin Hypertens 2011;3:523-528.

25 Nishizaka MK, Calhoun DA: The role of aldosterone antagonists in the management of resistant hypertension. Curr Hypertens Rep 2005;7:343-347.

$26 \mathrm{Li}$ YC, Kong J, Wei M, et al: 1,25-Dihydroxyvitamin $\mathrm{D}_{3}$ is a negative endocrine regulator of the renin-angiotensin system. J Clin Invest 2002;110:229-238.

27 Forman JP, Williams JS, Fisher ND: Plasma 25-hydroxyvitamin D and regulation of the renin-angiotensin system in humans. Hypertension 2010;55:1283-1288

28 Forman JP, Curhan GC, Taylor EN: Plasma 25-hydroxyvitamin D levels and risk of incident hypertension among young women. Hypertension 2008;52:828-832.

-29 Martins D, Wolf M, Pan D, et al: Prevalence of cardiovascular risk factors and the serum levels of 25-hydroxyvitamin D in the United States: data from the Third National Health and Nutrition Examination Survey. Arch Intern Med 2007;167:1159-1165.

30 Sugden JA, Davies JI, Witham MD, et al: Vitamin D improves endothelial function in patients with type 2 diabetes mellitus and low vitamin D levels. Diabet Med 2008;25:320325

31 Witham MD, Dove FJ, Dryburgh M, et al: The effect of different doses of vitamin $\mathrm{D}_{3}$ on markers of vascular health in patients with type 2 diabetes: a randomised controlled trial. Diabetologia 2010;53:2112-2119. 